\title{
Towards a Sustainable Small Non-Community Drinking Water System in Ontario: Owners' Risk Awareness and Perceptions to Water Safety
}

\author{
Mehmet Fatih Sekercioglu ${ }^{1}$, Jerry White ${ }^{2}$, Dan Shrubsole ${ }^{1} \&$ Jamie Baxter $^{1}$ \\ ${ }^{1}$ Department of Geography, Western University, London, Ontario, Canada \\ ${ }^{2}$ Department of Sociology, Western University, London, Ontario, Canada \\ Correspondence: Mehmet Fatih Sekercioglu, Department of Geography, Western University 1151 Richmond \\ Street, London N6A 3K7, Ontario, Canada. Tel: 1-226-700-3422. E-mail: msekerci@uwo.ca
}

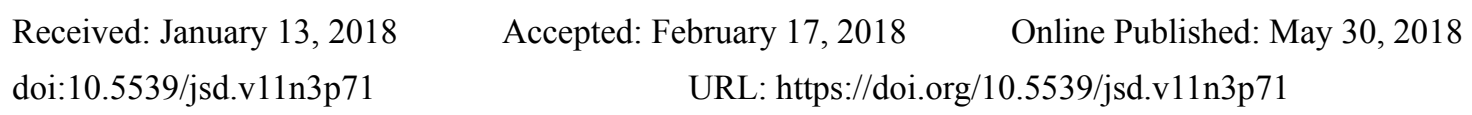

\begin{abstract}
In Ontario, small non-community drinking water systems are defined as systems that make drinking water available to the public and are not connected to a community drinking water system. This study, using qualitative research approach, examines the risk awareness and perceptions of small non-community drinking water system owners in providing safe drinking water to their clients and protecting their water source. Our study yields the need for developing a sustainable operation model for small non-community drinking water systems. The study results provide recommendations to the regulatory agency for effective and efficient administration of the program such as offering customized and affordable training opportunities and developing effective communication strategies for owners and operators.
\end{abstract}

Keywords: Ontario's water systems, risk awareness, risk perceptions, small drinking water systems, source water, sustainable water systems

\section{Introduction}

Waterborne disease outbreaks occur due to technical and/or operator failure at small, non-community drinking water systems throughout the developed world in places such as the Province of Ontario, Canada (Pons et al., 2015). What makes water quality management of Ontario's small non-community drinking water systems (SDWSs), which include facilities such as community centres, golf courses, libraries, motels, restaurants, churches and gas stations, important and relevant is the significantly different regulatory regimes that govern municipal water supplies and SDWSs. Furthermore, SDWSs have essentially been excluded from Ontario's relatively new source water protection framework. As a result of the current and emerging challenges including climate change effects, sustainable operation of SDWSs is crucial in ensuring the provision of safe drinking water. Sustainability of a water system depends on its operational capacity with adequate financial and technical support as well as social and environmental dimensions, and the regulatory regime (National Research Council, 1997).

Instead of public health units or Ministries of the Environment, which oversee Ontario's public water systems, the owners of SDWSs play fundamental roles in ensuring safe drinking water is provided from their treatment systems, and there has been a paucity of research concerning the efficacy of this approach. Our study aims to address this research need by describing and explaining the risk awareness and perceptions of drinking water system owners' in providing safe drinking water to their clients and protecting their sources of water from contamination.

As described in subsequent sections, a qualitative research approach is employed by conducting interviews with the SDWS owners. The regulatory agency for Ontario's SDWSs is the Ministry of Health and Long-Term Care (MOHLTC). Public health units represent the Ministry at the local level. The results of our study will provide insight for the regulatory agency for effective and efficient administration of the program. Furthermore, our study results will establish foundational principles to develop a sustainable operation model for SDWSs.

\subsection{Small Non-Community Drinking Water Systems in Ontario}

There is no universal definition of a SDWS. Within the Canadian context, the definitions and regulatory frameworks vary significantly among its provinces and territories. In Ontario, SDWSs are defined as systems 
that make drinking water available to the public and are not connected to a community drinking water system (Ministry of Health and Long-Term Care [MOHLTC], 2015). Since the MOHLTC assumed the responsibility as the regulator in 2008, over 9000 public water systems across Ontario have been identified as SDWSs drinking water systems, mostly located outside of the urban centres (Pons et al., 2014).

It is estimated that $20 \%$ of Ontario's population of 13.92 million people (Ministry of Finance, 2017) use SDWSs and this does not include transient users of these facilities, such as travelers. Therefore, the number of SDWS users is likely significantly higher, which further emphasizes the importance of ensuring safe drinking water in these systems (Pons et al., 2015). Furthermore, susceptible and vulnerable population groups, such as the elderly and young children, who are relatively more susceptible to diseases transmitted via unsafe drinking water are using these systems on a very regular basis.

\subsection{Some Recent Drinking Water Contamination Incidents}

Recent drinking water tragedies in Canada and the United States have heightened awareness of human and other errors. Just over a decade ago, the Walkerton (Ontario) drinking water tragedy occurred involving a public drinking water system. An outbreak of gastroenteritis caused seven deaths and affected over 2300 people in this outbreak and was the result of consuming contaminated water from the community drinking water systems in the Town of Walkerton (Hrudey et al., 2003). Along with other reasons, human error and inadequate water testing procedures played an important role in the occurrence of Walkerton tragedy (O'Connor, 2002).

Less than a year after the Walkerton tragedy, North Battleford's Cryptosporidium outbreak affected close to 7000 residents in the Province of Saskatchewan (Hrudey, 2011). Although no one was reported sick, the community water supply tested positive for Escherichia coli (E. coli) in Kashechewan First Nations, Ontario in 2005 which caused a massive evacuation of the community and drew attention to the community's ongoing water crisis for several years (Hrudey, 2011). Most recently, inadequately treated community drinking water in Flint, Michigan caused by chemical and microbiological contamination of the water affected 99,000 people between April 2014 and October 2015 (Kennedy et al., 2016; State of Michigan, 2016). The recent drinking water incidents figured heavily in how Canadians think about their water supplies.

Although not all of these incidents involved SDWS, the problems are actually magnified for them given that there is no mandatory management structure for SDWSs. Pons et al. (2015) reviewed the waterborne disease outbreaks in SDWSs in the United States and Canada between 1970 and 2014, and reported that untreated and inadequately treated water systems had been the leading cause of these outbreaks.

The $21^{\text {st }}$ Century's major drinking water contamination incidents in Canada, namely, Walkerton, Kashechewan, and North Battleford resulted in a comprehensive revision of drinking water management in Ontario. One of the outcomes was to amend the regulatory framework for SDWSs in Ontario.

\subsection{Regulatory Framework for SDWSs in Ontario}

Ontario's regulatory framework for drinking water is complex with the involvement of various stakeholders, which creates issues for the SDWS owners to figure out how to manage their systems on their own. Since the Walkerton tragedy, the provision of safe drinking water has become a priority for Ontario's government agencies. The Walkerton Inquiry Report (WIR) offered several recommendations to improve the drinking water management framework and served as a guide for all levels of government to demonstrate the best drinking water management practices (O'Connor, 2002). Yet, the challenge for SDWS owners to understand the legal responsibilities and demonstrate safe operational practices continues. Since the changes have been made based on the WIR's recommendations, better coordination among government agencies has been established.

The administration of the SDWS program is a unique example of this enhanced coordination among public institutions. To utilize and maximize this local capacity, the Ministry of the Environment transferred the oversight of SDWSs to the MOHLTC in 2008. Ontario's 36 public health units that represent the MOHLTC's regulatory role at the local level have a wealth of experience in inspecting local establishments open to the public such as food premises and public swimming pools.

Ontario Regulation 319 (Small Drinking Water Systems), enacted in 2008 under the Health Protection and Promotion Act, requires the owners of SDWSs to take responsibility for the provision of safe drinking water by complying with regulatory requirements (MOHLTC, 2015).

\subsection{Source Water Protection}

Source water protection (SWP) is a crucial step of the Multiple-Barrier Approach (MBA) as it addresses water quality by recognizing complex, multidimensional effects at the source. According to Justice Dennis O'Connor, 
protecting drinking water sources constitutes the first step to preventing contamination (O'Connor, 2002).

Establishing a source water protection safety net is an economic necessity because treating polluted water has been proven to cost more than keeping water clean at the source (Patrick, 2008). Also, social and environmental factors play a significant role in ensuring water sources are protected from contamination. SDWSs have been left out of Ontario's source water protection framework which causes discrepancy among systems, namely SDWSs and community drinking water systems, providing drinking water to the public. Including SDWSs and recognizing the perceptions of their owners is fundamental to ensure a better source water protection in Ontario. Thus, how owners manage their properties and interact with their neighbours and their properties can have a considerable impact on ensuring the safety of source water.

As noted above, contaminated water was one of the causes of the Walkerton tragedy, and protecting drinking water sources became a priority after this incident. Justice O'Connor (2002) made 17 recommendations in the WIR to establish the province's SWP framework. The provincial government acted on Justice O'Connor's (2002) recommendations by enacting several laws including the Safe Drinking Water Act in 2002, the Nutrient Management Act in 2002, and the Clean Water Act in 2006; and creating new institutions such as Source Water Protection Committees. The Clean Water Act establishes the legal framework for Ontario's SWP and stems from the application of the MBA principles (de Loë et al., 2016). This study will explore the possible consequences of the decision to exclude SDWSs from source water protection planning.

\subsection{Risk Literature}

The risk awareness and perceptions of the SDWS owners for the provision of safe drinking water and protecting water sources have been understudied. Examining the SDWS owners' perceived risks may be useful and beneficial for the regulator in creating an efficient and effective model for the SDWSs.

\subsubsection{Definition of Risk}

Risk is a subjective and multidimensional term with several definitions. Most of our day-to-day activities such as walking on the street, drinking a hot beverage involve some level of risk. Risk can simply be defined as the possibility of an adverse event and the magnitude of its consequence (Sjöberg et al., 2004). Eiser et al. (2012) define risk as a function of likelihood and value; whilst Slovic and Peters (2006) argues that risk is a natural reaction to danger. Given the fact that risk is a widely accepted norm, individuals often assess and perceive risk inaccurately (Jewel, 2009) and there are often differences in definition of risk between experts and lay public (Slovic, 2000). For ease of discussion, this study categorizes the regulatory agency representatives as 'experts' and the SDWS owners as 'lay public'.

In several instances such as the Walkerton tragedy, the water system operators' risk perception was no different than the lay public's perception of safe drinking water (Parr, 2004) therefore the risk was not assessed properly to respond with appropriate measures. Increasing risk awareness of the SDWS owners by offering training opportunities can potentially reduce the risk for the provision of unsafe drinking water.

Although earlier studies assessed risk within the context probability and magnitude parameters with an objective perspective; in recent decades the researchers widely accepted the subjectivity of risk (Slovic, 1997) and the need for multi-dimensional assessment by considering culture, location, societal factors (Slovic, 2000). Spence and Walters (2012) note that the water safety related research and policy work mostly examines the "objective dimensions" while the "subjective dimensions" are often neglected. The ongoing access to safe drinking water in Ontario's First Nations is a fine example to define the need for multi-dimensional approach to defining risk and recognizing its subjectivity. There is a significant difference in perceptions of water between Aboriginal and non-Aboriginal community members as Indigenous view defines 'water' a living thing with spiritual connection (Lavalley, 2006). To better communicate the risk and adequately train water system owners, cultural and societal factors should be considered and furthermore, the owner's risk perceptions are well understood. This study recognizes the subjective dimensions to examine risk awareness and perceptions of the SDWS owners.

\subsubsection{Risk Perception}

Since people often make decisions based on their risk perceptions, understanding how people interpret and respond to risks are as important as knowing possible outcomes (Brady, 2012). Elliott (2003) defines risk as a 'judgement' rather than a 'physical form' and argues that "perceptions of risk will depend heavily on assessments of the probability of an event and the severity of the impact, should the event occur" (p. 215). On the other hand, Brown (2014) notes the individual's frame of reference for risk perception as lifetime experience in addition to other emotional stressors. An important consideration for the regulatory agency should be recognizing the subjectivity of risk perception and ensuring the training programs and procedures are developed with extensive 
consultation with the SDWS owners. According to Sjöberg et al. (2004), the significant differences between the ways content experts and lay public perceive risk may create obstacles to rational decision making. Kraus et al. (1991) argue that experts should do a better job in explaining the risk to lay public and have consistent messaging. Considering the Town of Walkerton's water system operators lay public, the content experts which can be considered the regulatory agency employees at the time, there was a significant discrepancy regarding the definition and the parameters of safe drinking water (Parr, 2004). This study will contribute to closing the gap between content experts, public health inspectors and the targeted audience, the SDWS owners.

In some cases, lay public might consider an event or a condition as 'risky' where experts in that area could see little to no risk; the opposite is also true. Elliott (2003) agrees with Sjöberg et al. (2004) and summarizes key differences in risk frames used by professionals and the public in Table 1 . The recognition of considerable difference in defining, analyzing and accepting risk between environmental professionals and members of the public can be addressed by establishing effective and efficient risk communication strategies. When the regulatory agency communicates risks in the provision of safe drinking water to the SDWS owners, the aforementioned differences should be taken into consideration. Slovic (1987) defines the communication between lay public and experts 'a two-way process' and notes the need for respect and recognition for efficient and effective risk management and communication.

Table 1. Differences between professional and lay public risk frames (Elliott, 2003, p.216)

\begin{tabular}{|c|c|c|}
\hline & Environmental professionals risk frames & Lay public risk frames \\
\hline Meaning of risk & Expected value of loss & $\begin{array}{l}\text { Variability and potential for } \\
\text { extreme outcomes }\end{array}$ \\
\hline Method of inquiry & Analytic and conceptual & Experiential and reflective \\
\hline $\begin{array}{l}\text { Basis of trustworthy risk- } \\
\text { management systems }\end{array}$ & Reliable physical systems & Good people and institutions \\
\hline Acceptability of risk & Assessed relative to costs and other risks & $\begin{array}{l}\text { Preference for absolute reductions, } \\
\text { often to zero risk }\end{array}$ \\
\hline
\end{tabular}

Sjöberg et al. (2004) note "risk perception is the subjective assessment of the probability of a specified type of accident happening and how concerned we are with the consequences" (p.8) and argue that social and cultural norms play an important role in defining it. Brady (2012) agrees with Sjöberg et al. (2004) and notes that when individuals have knowledge and control over the hazard or event they perceive it differently compared to incidents where individuals have little or no control. Valerie (2014) also supports Sjöberg et al. (2004) and emphasizes the unconscious emotional processes individuals experience during risk perception. Compared to other jurisdictions, Ontario has the highest population depending on groundwater sources, yet the risk of unsafe drinking water from groundwater sources is not well understood (Nowlan, 2007). Furthermore, traditional approach to make drinking water laws with economic development focus has not shifted to enable new laws where sustainability, social and cultural norms are considered in the process (Nowlan, 2007). Recognizing subjectivity and valuing social and cultural norms in understanding the SDWS operator perception of risk in the provision of safe drinking water constitutes a foundation to build a framework that will serve the needs of the system owners and enhance the drinking water safety net.

Flynn et al. (1994) examine the effects of gender and race on perceptions of environmental health risks and report that females and non-white males perceive risk significantly different from white males. Gender and race are closely related to other social dimensions such as income, education and control over health risks (Flynn et al., 1994), therefore accepting and framing risk differ between individuals and socio-groups. Overall, risk perception is a subjective and multi-dimensional concept and listening to the SDWS owners is the first step to create an efficient and effective communication strategies for the SDWS program. This study addresses a significant gap in the current drinking water related research where the perspectives of SDWS owners may enhance the efficiency and effectiveness of the current program delivery model.

\subsection{Awareness and Risk Perception of Safe Drinking Water}

Understanding how managers interpret and respond to risks is as a key aspect of the changes in water management in Ontario and a consequence of downloading water protection (Brady, 2012). Considering the importance of judgment and individual frames of reference in the risk literature, risk perception is a subjective 
concept which varies from one person to the other. Castleden et al. (2015) examine the public health implications of drinking water-related behaviours and perceptions and conclude that an enhanced understanding of public perceptions related to drinking water safety results in developing effective communication strategies.

The recent Kashechewan and North Battleford drinking water contamination events in Canada, which were associated with community drinking water systems, resulted in a change in public behaviour towards tap water (Davids, 2006; Hrudey, 2011). These two events resulted in increased numbers of people preferring not to consume tap water and exploring alternatives such as bottled water (Dupont et al., 2010). Per unit volume, the cost of bottled water is between 240 to 10,000 times higher than tap water (Jaffee \& Newman, 2013; Saylor et al., 2011). Although there is no study examining the overall financial burden to increased bottled water use since Walkerton tragedy, the increase in the bottled water use is well documented (Jones et al. 2006; Jones et al.; 2007). Doria (2010) argues that past experiences affect the users' perceptions of water quality in tap water. Other studies conclude that the major contributing factor for Canadians deciding not to drink tap water is their perceived potential health concerns (Jones et al. 2006; Jones et al., 2007; Dupont et al., 2010; McLeod et al., 2014).

Social determinants of health, such as the conditions in which people live and work contribute to the development of risk perception. To explore the social determinants of health for the provision of drinking water, it is fundamental to investigate downstream factors such as the attitudes and behaviours of water system owners and operators. These downstream behaviours are underpinned by upstream determinants such as social, economic and environmental factors (Bravemen et al., 2011). Also, recognizing the level of adaptive capacity, the ability to respond to change, provides a sound foundation to create sustainable water system operations. There is a gap in knowledge and literature which needs to be filled by conducting further investigation. This study aims at closing this gap by focusing on the attitudes and perceptions of the SDWS owners within the context of social determinants of health and examines the effect of social, economic and environmental factors on the provision of safe drinking water in SDWSs.

The Walkerton tragedy affected the public's perception of drinking water from community water systems (Turgeon et al., 2004). Parr (2004) examines Walkerton residents' perceptions towards safe drinking water before and after the tragedy and the effects of these perceptions, especially in the earlier stages of the tragedy. The Walkerton residents' perception of safe drinking water was based on parameters such as taste, thrift, and smell. Moreover, respondents perceived that the chlorine-added drinking water as low-quality tap water (Parr, 2004). Other studies also confirm the importance of aesthetic factors in the public's perception of safe drinking water (Doria et al., 2009; Doria, 2010; McLeod et al., 2014); yet the literature lacks information regarding the perceptions of water system owners.

There are other factors that affect perception. Drinking water safety, especially in smaller communities, requires collaboration among water management officials and residents as the operation of water systems results in significant expenses. According to Johnston (2008), the public considers chemicals with which they are familiar such as lead and arsenic riskier than those that are less familiar such as cadmium, perchlorate, even though they pose the same level of concern based on the regulatory limits.

Although several studies and reports (Davids, 2006; Doria, 2010; Dupont et al. 2010; Hrudey, 2011; McLeod et al., 2014; O'connor, 2002) examined the drinking water users' risk awareness and perceptions regarding tap water in general populations, there is a clear gap in the research literature documenting the perspectives of the drinking water system owners who provide drinking water from their systems. The results of this study will enhance the ability to actively apply the current knowledge into new program where the SDWS owners' risk awareness and perceptions in the provision of safe drinking water are considered.

\section{Methods}

\subsection{Research Area}

The study was carried out in one health unit in Ontario, Canada and the strategy for selection being in a central location as well as having a rural and urban mix in its geography. Of the 36 health units in Ontario, the majority (29) are located in Southern Ontario. The study region is Wellington-Dufferin-Guelph Public Health's jurisdiction which includes Wellington and Dufferin Counties, and the City of Guelph. This region is centrally located in Southern Ontario, is 98\% rural and 2\% urban with 229 SDWSs (Wellington Dufferin Guelph Public Health, 2016). Acknowledging its central location and the number of systems, this region provides a good representation for Southern Ontario.

\subsection{Participants}

Sixteen SDWS owners in Wellington-Dufferin-Guelph region participated the interview. They came from all 
major types of businesses such as golf course, summer camp, restaurant, community centre, church, recreational facility, municipal building, and conservation area. All participants owned their systems for five or more years, and seven of the owners lived on the property where the system was located. Fourteen of the participants were both owner and water system operator. Being both an owner and operator is a common practice in SDWSs as hiring a water system operator is often cost prohibitive.

\subsection{Data Collection}

The researcher scheduled in-person or telephone interviews with the SDWS owners, who participated in the study. For the interviews, the first preference was meeting face-to-face at a time and venue chosen by the study participant. When meeting in-person was not possible, a telephone interview was conducted at a mutually convenient time. All participants had the study clearly explained and informed consent was secured. There was no financial compensation for their participation in the study.

The interviews were face-to-face $(\mathrm{n}=10)$ and over the telephone $(\mathrm{n}=6)$, and took between 35 and 90 minutes. The interviews were audio recorded and later transcribed by the researcher. The analysis was managed using NVivo (Richards, 1999). The use of inductive grounded theory enabled an iterative and interactive approach to construct theory from data (Charmaz, 2012; 2006). When the saturation point is reached, it means sufficient perceptions are collected and the new data would not change the newly generated approach (Tolhurst, 2012), In this study, the perceptions and concepts became evidently similar by the 12th interview and the researcher continued the interviewing with a few more participants to ensure no new information and perspective were disclosed or discussed. As a result, the interviews were concluded when the saturation point was reached after 16 participants. The Information Letter, Consent Form, and Interview Guide were submitted to Western University's Research Ethics Board (REB) and received the approval in September, 2016.

The research data included interview transcripts. Interviews were recorded with an audio recorder with participant consent. To increase rigour, the member checking process was used (Baxter and Eyles, 1997). The results, discussion and conclusion sections, a total of 14 pages were shared with each study participant to provide them an opportunity for review and further input. The participants were also provided with the transcript of the interview upon request. Out of 16 participants, nine of them responded and were satisfied with the results and interpretations.

The audio-recorded interviews were transcribed, verbatim, by the researcher. The interview data were analyzed by using NVivo9 ${ }^{\mathrm{TM}}$, a qualitative data management software program. To gain insight and knowledge from the data and identify common themes, Thematic Analysis was employed. Vaismoradi et al. (2013) define Thematic Analysis as an "independent and a reliable qualitative approach to analysis" (p.400). According to Clarke and Braun (2017), TA brings flexibility and accessibility which results in generating useful results from the data collected. Although TA initially explains the importance of themes for the research purpose, the identified themes exist independently when the analysis is completed (Ho et al., 2017). Counting will be used through the results section to provide context for recognition of patterns (Sandelowski, 2001).

\section{Results}

The interview guide topics included operational practices, water safety, training, communication. The analysis of the interview data from the 16 SDWS owners yielded five main themes as explained below.

\subsection{Theme 1: I Also Drink the Water}

The majority of participants reported that their families also used the water supplied by SDWSs, which brought the conversations to a personal level and constituted a higher level of risk perception. Jane, owner of a golf course stated: '...Because I live here water is safe for my family not just for my customers. I think it has a bigger role that water is safe as I am drinking it too. it sounds selfish but it is real.'

Lisa who owns of a health and fitness club revealed: 'There is no hiding anything, all of our employees, all of our family, club members take water from the same system.'

When participants were asked to describe their water systems and discuss their operational challenges, all of the respondents appeared to have a sense of ownership and responsibility. Five of the respondents experienced a challenge to describe and discuss their systems' operational challenges because of competing priorities in their day-to-day business tasks. James described the reliance on the regulatory agency and lack of knowledge regarding operational processes: 'Probably little lack of knowledge with respect to what we are doing, as everything is requested by the current Ministry of Health.' Four participants discussed the occasional mechanical and treatment system malfunctions and noted the importance of acting promptly when those issues arose. 
In response to the question "Please explain the importance of regularly testing your SDWS", all the participants indicated that testing was an important step in the provision of safe drinking water and commented on the procedural and legal liability. Lisa stated: 'We have the responsibility by law to test it regularly. As soon as we learned about the risks and all that, we quickly hired an outsourced company...' Out of 16 participants, two of them delegated the full responsibility to an outsourced company to operate their SDWSs.

Michelle, a golf course owner, also commented on the importance of regularly testing: '...Should anything ever happen, accidents happen, we have a good record of showing due diligence...'

Nicole who owns a trailer park discussed the benefits of testing: 'You have that peace of mind that you do not need worry about anything...I am also drinking the water myself here directly.'

The participants were also asked what they knew about their source water. Respondents were able to demonstrate the knowledge about the location of their wells but the majority of the participants raised concerns regarding lack of control over surrounding areas as it may affect the safety of their water source. The conversations mainly focused on the agricultural or commercial activities of their neighbours, and the potential effects of those activities on ground water quality where they had no control. Another golf course owner, Jane, illustrated the external factors that may affect the water quality:

'There is large 200 acres' potato farm across from us who sprays and we keep the dog inside the house, close our windows, two or three times a year they rotate their crops corn to potatoes to nothing so that would be a possible source of contamination.'

Chemical contamination risk was not considered an issue for 12 of the owners. The participants associated the risk of chemicals in drinking water with possibility of chemical spill. Nicole revealed: 'We don't have any dangerous industry people using chemical that can get into the water system, and there is nothing in our proximity.'

Escherichia coli was considered the most serious contamination risk. Nine respondents made reference to the Walkerton tragedy when answering the questions related to water safety. Lori summarized health effects of unsafe drinking water in one short sentence: 'Illness or death, Walkerton always comes to mind.' Lisa stated: 'Ever since Walkerton everybody takes drinking water a lot more serious. Everybody used to think all the water in Canada was safe.' Nicole also commented on the same issue: 'I guess Walkerton was the fine example of that, people neglected the system and it did happen.'

The participants were asked to react to the following statement: "When people get sick, drinking water can be the source of illness". While 12 respondents acknowledged the potential link between people getting sick and unsafe drinking water, three participants talked about the possibility of contamination from sources other than water such as food. Participants showed confidence in the safety aspect of drinking water from public water systems. The interview discussions revealed high levels of knowledge and awareness of the SDWS owners regarding the possibility of unsafe drinking water causing illness.

\subsection{Theme 2: Revenue and Business Reputation Loss}

The participants strongly associated unsafe drinking water with reputation and revenue loss and demonstrated unwavering vigilance for adverse water quality incidents. Jessica owns a recreational camp with thousands of visitors from Canada and across the world every year. Her reaction to an adverse water quality incident at her facility was:

If there is something wrong with our water, we shut down. There is no question. There are health implications, legal implications, water is everything. If you do not have good water, you do not function.'

Jessica continued: 'I like to protect people who come here. I am more worried about that than getting a fine because I did not do something.'

Thus safe drinking water is linked to business reputation. The respondents commented on the detrimental effect of unsafe drinking water on their business. Bob, the owner of a tourist attraction that provides drinking water to hundreds of visitors every year stated:

'...you kind of take it for granted until you do not have it at your disposal, and you realize how absolutely important water and good quality water is to the operations.'

Joe's input on the business reputation as a result of unsafe drinking water was similar to the other participants: 'We can lose customers, would not have anyone coming here, lots of complaints from people, increased fear from some people to come here. 'Lisa echoed several other participants' perspective: '...if we do not test it and we get 
into some trouble, that would cost us our business.'

The respondents showed empathy towards other well owners in their local community. James drew attention to potential impact on the community during an unsafe drinking water occurrence: "It would have huge effects on the community. Everybody here is on well system. If groundwater is affected, it would affect all the rural houses.'

\subsection{Theme 3: Financial Constraints}

There were several comments regarding the financial constraints being a potential barrier. Jeremy highlighted the importance of testing with a reservation on the cost: 'Regular testing is important as long as it does not cost a lot and can be managed by local resources.' The participants expressed concerns about the lack of knowledge in best operational practices and sampling techniques where adverse water quality incidents occur if the proper steps are not followed.

Lori, the owner of a rural restaurant gave an example when proper sampling steps were not followed and retesting was required with an added cost: '... But even taking a water sample improperly could cause an adverse effect on your water sample. Because the one that came wrong was taken by my husband who did not know what he was doing, not to blame him but I took small drinking water course once and I do believe that there is a lot to learn.

Adam, the owner of a summer camp experienced financial constraints: I cannot afford to go to training but I have it from my previous experience.' Another participant, Philip who owns a recreational camp had a similar perspective with Adam: 'You can train people with so many little things, so we are not like a big company that has training budget for everything they do but it is important a number of people know how the system works.'

\subsection{Theme 4: Value of Training}

The respondents revealed the importance of training for the provision of safe drinking water in SDWSs. Barret illustrated the necessity for increased training: 'The requirements of the health unit are very simple but training should happen to be aware of the sampling procedures and what to do in case of an adverse result.'

As the systems are different from each other, Barrett noted: 'Training is important and it is also important that the training be appropriate to the level of complexity of the system.' Seven out of 16 respondents discussed the importance of sampling procedures and revealed that not following the recommended sampling procedures previously resulted in an adverse water quality incident in their system. Although the chemical contamination possibility was discussed in several interviews, the owners were not provided with adequate knowledge and tools to assess potential chemical contamination threats to their water supplies.

Participants also discussed the need for better communication of the training opportunities. Jane commented on the ambiguity in the types of training courses and provided example: 'Source water protection knowledge, I would say it is very important but I don't feel that I had a good training in that.'

\subsection{Theme 5: Disconnected}

The participants were asked if drinking water safety came up in conversations with other SDWS owners. The responses clearly demonstrated the fact that the owners do not have a network to discuss these issues. The sense of community seemed to be lacking as participants mainly felt isolated. Lori, the owner of a rural restaurant commented on communication: 'I do not think I have heard anyone discussing this issue...not a lot of communication happening. 'Lisa revealed: 'I have not heard of any other SDWSs in this area.'

Another question inquired about the best way to communicate with the SDWS owners. The responses did not yield one preferred method of communication as the respondents had different preferences on the most effective communication method and receiving updates from the regulator.

Barret commented: 'I would like hard copy mails. I like paper...I have a binder with a tab on water system, everything from the health unit.' Lisa shared Barret's perspective:

I do not think email will do it; there are just too many emails from different sources. If I get a hard copy mail from public health versus email, it is harder to miss. E-mails go rounds sometimes, it can go spam filter and you can miss it and you do not realize you missed it.'

On the other hand, some respondents preferred email communication over the hard copy mail. According to Adam: 'Two ways of communication would be more efficient, email is one of them and meetings are very important...' 'Dave who owns a recreational facility commented: 
'I think emails would be the best, having kind of an email protocol, of there is anything in the area or there are updates we would automatically get emails...meeting in person would be excellent, once a year or twice a year.'

Lori also supported the email communication: 'My preference would most likely be an email. Because if I have an email, I can read it, and save it and throw it in a file to reference back to it.'

12 out of 16 participants were dissatisfied with the communication they received from the government and considered the communication as the biggest gap. All of the participants agreed that there was a need for organizing regular local meetings with government representatives. These meetings would not only provide updates but would also enhance communication among the SDWS owners.

\section{Discussion}

Qualitative methods employed in this study provided insight into SDWS owners' awareness and perceptions about the provision of safe drinking water and source water protection. Our results indicated key parameters to establish a sustainable operation for SDWS and also led to a series of recommendations we make in this article to revamp the communication strategy for the SDWS owners.

The SDWS owners were aware of the health risks of unsafe drinking water and demonstrated sense of ownership and responsibility to provide safe drinking water to their users. In many cases, their family members have been using the same water as they were either living on site or visiting their businesses. This was important as Madrigal and Alpízar (2011) argues that lack of ownership and motivation results in poor operational performance in drinking water systems.

Losing revenue and business reputation was among the major driving forces to ensure the water system is operated in compliance with regulations. Some owners contracted out the regular maintenance services to ensure the operational and regulatory requirements are fully met. The SDWS owners' responses about their awareness and perceptions were significantly influenced by the Walkerton tragedy. Their motivation stemmed from awareness of the health consequences of drinking unsafe water, business reputation, revenue loss and participants and their families drinking the same water. Our study results support the previous findings (Dupont et al., 2010; McLeod et al., 2014) regarding perceived potential health concerns to drink tap water. This perceived risk has a positive effect on the provision of safe drinking water in SDWSs. In addition, family members drinking the water from SDWS also elevates the perceived risk (Janmaimool \& Watanabe, 2014). It is important to note that owners of SDWSs did not share the change in public behaviour towards tap water as Dupont at al. (2010) argued. Instead, participants of the study praised the safety of water from public drinking water systems. The study results support the findings of Brady (2012) and Sjöberg et al. (2004) regarding risk perceptions towards the events people have control over, as such SDWS owners showed confidence in water from SDWSs.

Although water system failures similar to the ones associated with water-related disease outbreaks do occur in SDWSs, the owners are strongly motivated to rectify the issues in a timely manner. In addition to adequate operational practices, raising awareness for source water protection among the SDWS owners would play an instrumental role in the provision of safe drinking water in SDWSs. Establishing systems to monitor water quality and assess the risks from source to tap will confine the effects of adverse water incidents (Patz et al. 2008). Currently, there is no system in place to monitor, assess, and when necessary, remediate any kind of contamination in source water.

The study results revealed the need for increased attention to protecting drinking water sources. Although source water protection is a fundamental step of the Multi-Barrier Approach to ensure safe drinking water, SDWSs have not been included in Ontario's Source Protection Plans. The owners of the systems face significant challenges to protect their water sources and need a structured approach. A wellhead protection model similar to the one proposed by Frind et al. (2006) where contaminant types and aquifer structure is considered may be a viable option to support SDWS owners in protecting their water sources.

Hrudey (2011) argues that although the main focus for drinking water safety discussions has been the microbiological parameters, there is a growing concern regarding the chemical parameters and their potential long-term effects to cause illnesses such as cancer. This supports the study findings as participants did not seem to be concerned about chemical contamination of their water. As Justice O'Connor (2002) noted, the drinking water safety risk should be measured by considering all relevant parameters and appropriate preventive measures should be taken to address concerns regarding those parameters. The study participants focused exclusively on industrial contamination possibility during the discussions about chemical parameters of their drinking water and 
did not mention about naturally occurring chemicals or farming activities nearby as potential issues. The lack of awareness may be due to the fact that the regulatory agency does not require routine testing for chemicals.

Financial constraints have been one of the main themes during the interviews. Participants shared their financial constraints as they had been trying to meet the regulatory requirements. Two activities they felt financial challenges were: 1 . Testing their water for microbiological and chemical parameters; 2. Accessing to training opportunities.

The regulatory agency should develop strategies to raise awareness for chemical contaminants in drinking water and furthermore, reduce barriers to offer low-cost training and subsidized water testing opportunities.

Climate change will increase the frequency of extreme weather events such as floods and droughts and consequently cause the elevated risk of waterborne disease outbreaks (Patz et al., 2008). SDWSs may not have sufficient resources and capacity to eliminate the adverse effects of extreme weather events which puts the safety of drinking water at risk. Dow et al. (2007) investigate the perceptions of water system managers about climate change effects and identify water quality, financial impact and scarcity of supply as major concerns. The study participants indicated financial concerns and limited water quality intervention potential which makes SDWSs prone to climate change impacts. The SDWS owners should be made aware of potential risks that can compromise the provision of safe drinking water and the regulatory agency should consider strategies to support the owners of these systems to be prepared for the potential effects of climate change.

The perception of drinking water safety based on social, economic and environmental factors may potentially conflict with regulatory requirements. Until the Walkerton tragedy, the town residents and water system operators had a strong belief regarding the safety of groundwater from a well without treatment and considered the treatment process such addition of chlorine causing impurity in their water (Parr, 2004). The information provided by Public Health Inspectors was highly valued by the study participants therefore maintaining this relationship and enhancing it by developing new communication strategies

The respondents highly valued the information and guidance provided to them by Public Health Inspectors and therefore there was continued interest in learning more from the regulatory agency and complying with the regulatory requirements. Cox (2015) suggests focusing on participants' life experiences as well as social interactions, beliefs in training program design. The training programs for the SDWS owners should recognize different perspectives and integrate social determinants of health in addition to regulatory mandates. It is also important to note that programs or interventions that are designed to influence behaviour change are more successful when they target specific behaviours with an understanding of factors influencing that behaviour (Abraham \& Michie, 2008). The SDWS owners seemed very keen on accessing training and networking opportunities initiated by government agencies with the expectation that these opportunities would not be cost prohibitive.

The study results yielded the lack of sense of community among SDWS owners. Feeling of isolation was a common response by the participants. There is a significant need to establish and foster relationships so that the SDWS owners can regularly interact with each other. Creating a sense of community among local SDWS owners is a step in the right direction for the regulatory agency. All of the study participants were favourable to the idea of semi-annual meetings to receive updates and interact with other SDWS owners.

The SDWS owners raised concerns regarding the level of communication they had been receiving from the regulatory agency. This study generated some interesting results regarding the communication preferences of the SDWS owners. Based on the interview results, sharing the regular updates with the owners of SDWS owners by using both regular mails and electronic mails will ensure the updates are received by the target audience.

Overall, the study results provide valuable information for all of the stakeholders in water management systems. Investigating the current challenges of the SDWSs owners was an integral step to bridge the gap between practice and theory and established a foundation to develop an efficient and effective SDWS management program.

\section{Conclusion}

This study examines the risk awareness and perceptions of SDWS owners in the provision of safe drinking water and protecting their water source, and provides recommendations to the regulatory agency for effective and efficient administration of the SDWS program.

The SDWS owners are aware of the financial and non-financial consequences of an adverse water quality event, but nevertheless, they have not been offered opportunities to receive adequate training on best operational practices and assessing potential threats to their water source. According the study results, training opportunities 
initiated by the regulatory agency with a reasonable cost have the potential to gauge a lot of interest. On the other hand, the SDWS owners face financial challenges to meet the operational requirements such as regular water testing and operator training. The regulatory agency should establish mechanisms to provide financial relief which could include providing subsidy on water testing and low-cost training opportunities.

One particularly interesting result of this study is that the SDWS owners feel isolated, mainly for the following two reasons: 1) There is a certain level of disconnect as they do not receive regular communication from the regulatory agency; 2) They lack of a sense of community among the SDWS owners in the same region. The study results reveal the method of communication preferences that assist the regulatory agency in establishing new mechanism to stay connected with the SDWS owners.

Although the study design had several strengths and the saturation point was reached, the number of participants was a limitation. The participation opportunity was given to all SDWS owners in the region and the ones who accepted the invitation after the researcher's efforts to recruit for participation in the study were interviewed. The representation from all major types of businesses was achieved.

Notwithstanding the identified limitation, the study yielded fruitful results for enhancement of the SDWS program by the regulator. Emerging environmental concerns such as more frequent extreme weather events will put water sources at risk of contamination and subsequently, SDWSs might be prone to operational and water source challenges.

It would be timely for the regulatory agency to develop effective communication strategies to support the owners and operators. Lastly, customized and affordable training opportunities are also key for success in increasing the awareness and knowledge in the provision of safe drinking water.

\section{References}

Abraham, C., \& Michie, S. (2008). A Taxonomy of Behaviour Change Techniques Used in Interventions. Health Psychology, 27(3), 379-387.

Baxter, J., \& Eyles, J. (1997). Evaluating Qualitative Research in Social Geography: Establishing 'Rigour' in Interview Analysis. Transactions of the Institute of British Geographers, 22(4), 505-525. https://doi.org/10.1111/j.0020-2754.1997.00505.x

Brady, J. T. (2012). Health risk perceptions across time in the USA. Journal of Risk Research, 15(6), 547-563. https://doi.org/10.1080/13669877.2011.643476

Braveman, P., Egerter, S., \& Williams, D. R. (2011). The social determinants of health: Coming of age. Annual Review of Public Health, 32(1), 381-398. https://doi.org/10.1146/annurev-publhealth-031210-101218

Brown, V. (2014). Risk Perception: It’s Personal. Environmental Health Perspectives, 122(10), A276-279.

Castleden, H., Crooks, V. A., \& van Meerveld, I. (2015). Examining the public health implications of drinking water-related behaviours and perceptions: A face-to-face exploratory survey of residents in eight coastal communities in British Columbia and Nova Scotia: Surveying drinking water perception in BC and NS coastal communities. The Canadian Geographer, 59(2), 111-125.

Charmaz, K. (2006). Constructing grounded theory: A practical guide through qualitative analysis. London: Sage Publications.

Charmaz, K. (2012). The Power and potential of grounded theory. Medical Sociology Online, 6(3), 2-15.

Clarke, V., \& Braun, V. (2017). Thematic analysis. The Journal of Positive Psychology, 12(3), 297-298. https://doi.org/10.1080/17439760.2016.1262613

Cox, E. (2015). Coaching and adult learning: Theory and practice. New Directions for Adult and Continuing Education, 148, 27-38 https://doi.org/10.1002/ace.20149

Creswell, J. W., \& Miller, D. L. (2000). Determining validity in qualitative inquiry. Theory into Practice, 39, 124-134. https://doi.org/10.1207/s15430421tip3903_2

Davids, J. (2006). From The Tap Newsletter. Retrieved from http://www.mcmillan.ca/Files/FTT_Inferior\%20Protection_First\%20Nations_0206.pdf

de Loë, R. C., Murray, D., Michaels, S., \& Plummer, R. (2016). Policy transfer among regional-level organizations: Insights from source water protection in Ontario. Environmental Management, 58(1), 31-47. https://doi.org/10.1007/s00267-016-0699-x

Doria, M. d. F. (2010). Factors influencing public perception of drinking water quality. Water Policy, 12(1), 1-19. 
https://doi.org/10.2166/wp.2009.051

Doria, M. d. F., Pidgeon, N., \& Hunter, P. R. (2009). Perceptions of drinking water quality and risk and its effect on behaviour: A cross-national study. Science of the Total Environment, 407(21), 5455-5464. https://doi.org/10.1016/j.scitotenv.2009.06.031

Dow, K., O'Connor, R. E., Yarnal, B., Carbone, G. J., \& Jocoy, C. L. (2007). Why worry? community water system managers' perceptions of climate vulnerability. Global Environmental Change, 17(2), 228-237. https://doi.org/10.1016/j.gloenvcha.2006.08.003

Dupont, D., Adamowicz, W. L., \& Krupnick, A. (2010). Differences in water consumption choices in Canada: the role of socio-demographics, experiences, and perceptions of health risks. Journal of Water and Health, $8(4), 671-686$.

Eiser, R. J., Bostrom, A., Burton, I., Johnston, D. M., McClure, J., Paton, D., ... White, P. M. (2012). Risk interpretation and action: A conceptual framework for responses to natural hazards. International Journal of Disaster Risk Reduction, 1, 5-16. https://doi.org/10.1016/j.ijdrr.2012.05.002

Elliott, M. (2003). Risk perception frames in environmental decision making. Environmental Practice, 5(3), 214-222. https://doi.org/10.1017/S1466046603035609

Flynn, J., Slovic, P., \& Mertz, C. K. (1994). Gender, Race, and Perception of Environmental Health Risks. Risk Analysis, 14, 1101-1108. https://doi.org/10.1111/j.1539-6924.1994.tb00082.x

Frind, E. O., Molson, J. W., \& Rudolph, D. L. (2006). Well vulnerability: A quantitative approach for source water protection. Ground Water, 44(5), 732-742. https://doi.org/10.1111/j.1745-6584.2006.00230.x

Ho, K. H. M., Chiang, V. C. L., \& Leung D. (2017). Hermeneutic phenomenological analysis: the 'possibility' beyond 'actuality' in thematic analysis. Journal of Advanced Nursing, 73(7), 1757-1766. https://doi.org/10.1111/jan.13255

Hrudey, S. E. (2011). Safe Drinking Water Policy for Canada: Turning Hindsight into Foresight. C.D., Howe Institute. Retrieved April 12, 2017, from http://www.cdhowe.org/pdf/Commentary_323.pdf

Hrudey, S. E., Huck, P. M., Gillham, R. W., \& Hrudey, E. J. (2003). A fatal waterborne disease epidemic in Walkerton, Ontario: Comparison with other waterborne outbreaks in the developed world. Water Science and Technology, 47(3), 7-14. https://doi.org/10.1139/s02-031

Ivey, J. L., de Loë, R. C., \& Kreutzwiser, R. D. (2006). Planning for source water protection in Ontario. Applied Geography, 26(3-4), 192-209. https://doi.org/10.1016/j.apgeog.2006.09.011

Jaffee, D., \& Newman, S. (2013). A bottle half empty: Bottled water, commodification, and contestation. Organization \& Environment, 26(3), 318-335. https://doi.org/10.1177/1086026612462378

Janmaimool, P., \& Watanabe, T. (2014). Evaluating Determinants of Environmental Risk Perception for Risk Management in Contaminated Sites. Int. J. Environ. Res. Public Health, 11, 6291-6313. https://doi.org/10.3390/ijerph110606291

Jewell, N. P. (2009). Risk Interpretation, Perception, and Communication. American Journal of Ophthalmology, 148(5), 636-638. https://doi.org/10.1016/j.ajo.2009.06.019

Johnson, B. B. (2008). Public views on drinking water standards as risk indicators. Risk Analysis, 28(6), 1515-1530. https://doi.org/10.1111/j.1539-6924.2008.01116.x

Jones, A. Q., Dewey, C. E., Doré, K., Majowicz, S. E., McEwen, S. A., David, W., \& Henson, S. J. (2006). Public perceptions of drinking water: A postal survey of residents with private water supplies. BMC Public Health, 6(1), 94. https://doi.org/10.1186/1471-2458-6-94

Jones, A. Q., Majowicz, S. E., Edge, V. L., Thomas, M. K., MacDougall, L., Fyfe, M., Atashband, S., \& Kovacs S. J. (2007). Drinking water consumption patterns in British Columbia: An investigation of associations with demographic factors and acute gastrointestinal illness. In Science of the Total Environment, 388(1-3), 54-65. https://doi.org/10.1016/j.scitotenv.2007.08.028

Kennedy, C, Yard, E., \& Dignam, T. (2016). Blood Lead Levels Among Children Aged $<6$ Years — Flint, Michigan, 2013-2016. MMWR Morb. Mortal. Wkly. Report, Vol. 65.

Kraus, N., Malmfors, T., \& Slovic, P. (1992). Intuitive toxicology: Expert and lay judgments of chemical risks. Risk Analysis, 12(2), 215-232. https://doi.org/10.1111/j.1539-6924.1992.tb00669.x

Lavalley, G. (2006). Aboriginal Traditional Knowledge and Source Water Protection: First Nations' Views on 
Taking Care of Water. Report prepared for Chiefs of Ontario and Environment Canada. Toronto, ON: Chiefs of Ontario.

Lewis, J. (2009). Redefining Qualitative Methods: Believability in the Fifth Moment. International Journal of Qualitative Methods, 8(2), 1-14. https://doi.org/10.1177/160940690900800201

Ligon, G., \& Bartram, J. (2016). International journal of environmental research and public health: Literature review of associations among attributes of reported drinking water disease outbreaks, Int. J. Environ. Res. Public Health, 13(6), 527. https://doi.org/10.3390/ijerph13060527

Madrigal, R., \& Alpízar, F. (2011). Determinants of performance of community-based drinking water organizations. World Development, 39(9), 1663-1675. https://doi.org/10.1016/j.worlddev.2011.02.011

McLeod, L., Bharadwaj, L., \& Waldner, C. (2014). Risk Factors Associated with the Choice to Drink Bottled Water and Tap Water in Rural Saskatchewan. International Journal of Environmental Research and Public Health, 11(2), 1626-1646. https://doi.org/10.3390/ijerph110201626

Ministry of Finance. (2017). Ontario Fact Sheet, September 2017. Retrieved from https://www.fin.gov.on.ca/en/economy/ecupdates/factsheet.html

Ministry of Health and Long-Term Care (MOHLTC). (2015). Small Drinking Water Systems. Retrieved from http://www.health.gov.on.ca/english/public/program/pubhealth/safewater/safewater_faq.html

National Research Council. (1997). Safe Water from Every Tap: Improving Water Service to Small Communities. Washington, DC: The National Academies Press.

Natural Resources Canada. (2006). Canada Political Divisions. Retrieved from http:/www.nrcan.gc.ca/earth-sciences/geography/atlas-canada/reference-maps/16846\#canada

Nowlan, L. (2007). Out of Sight, Out of Mind? Taking Canada's Groundwater for Granted. In K. Bakker (Eds.), Eau Canada, Vancouver, BC: UBC Press.

O'Connor, D. R. (2002). Report of the Walkerton inquiry: Part two, A Strategy for Safe Drinking Water. Toronto, Ontario: Ontario Ministry of the Attorney General, Queen's Printer for Ontario.

Ohio Environmental Protection Agency (OEPA). (2015). Source Water Assessment and Protection Program. Retrieved

from http:/www.epa.ohio.gov/ddagw/swap.aspx\#119996097-whats-the-difference-between-the-source-water-pro tection-swap-program-and-the-wellhead-protection-whp-program

Parkes, M. W., Morrison, K. E., Bunch, M. J., Hallström, L. K., Neudoerffer, R. C., Venema, H. D., \& Waltner-Toews, D. (2010). Towards integrated governance for water, health and social-ecological systems: The watershed governance prism. Global Environmental Change, 20(4), 693-704. https://doi.org/10.1016/j.gloenvcha.2010.06.001

Parr, J. (2005). Local water diversely known: Walkerton, Ontario 2000 and after. Environment and Planning D, Society and Space, 23(2), 251-271. https://doi.org/10.1068/d431

Patrick, R. J. (2008). A political ecology of source water protection. Prairie Perspectives, 12, 43-62.

Patz, J. A., Vavrus, S. J., Uejio, C. K., \& McLellan, S. L. (2008). Climate change and waterborne disease risk in the great lakes region of the U.S. American Journal of Preventive Medicine, 35(5), 451-458. https://doi.org/:10.1016/j.amepre.2008.08.026

Pons, W., McEwen, S. A., Pintar, K., Jones-Bitton, A., Young, I., \& Papadopoulos, A. (2014). Experience, training and confidence among small, non-community drinking water system operators in Ontario, Canada. Journal of Water \& Health, 12(4), 782-790.

Pons, W., Young, I., Truong, J., Jones-Bitton, A., McEwen, S., Pintar, K., \& Papadopoulos, A. (2015). A systematic review of waterborne disease outbreaks associated with small non-community drinking water systems in Canada and the United States. PLoS One, 10(10), E0141646. https://doi.org/10.1371/journal.pone.0141646

Richards, L. (1999). Data alive! the thinking behind NVivo. Qualitative Health Research, 9(3), $412-428$. https://doi.org/10.1177/104973239900900310

Sandelowski. (2001). Real qualitative researchers do not count: the use of numbers in qualitative research. Res Nurs. Health., 24(3), 230-40. https://doi.org/10.1002/nur.1025

Saylor, A., Prokopy, L., \& Amberg, S. (2011).What's wrong with the tap? examining perceptions of tap water 
and bottled water at Purdue university. Environmental Management, 48(3), 588-601. https://doi.org/10.1007/s00267-011-9692-6

Sjöberg, L., Moen, B., \& Rundmo, T. (2004). Explaining risk perception. An evaluation of the psychometric paradigm in risk perception research. Rotunde publikasjoner, Rotunde no. 84.

Slovic, P. (1987). Perception of risk. Science, 236, 280-285.

Slovic, P. (1997). Public perception of risk. Journal of Environmental Health, 59(9), 22-23.

Slovic, P. (2000). The perception of risk. Sterling, VA; London: Earthscan Publications.

Slovic, P., \& Peters, E. (2006). Risk perception and affect. Current Directions in Psychological Science, 15(6), 322-325. https://doi.org/10.1111/j.1467-8721.2006.00461.x

Spence, N., \& Walters, D. (2012). Is it Safe? Risk Perception and Drinking Water in a Vulnerable Population. International Indigenous Policy Journal, 3(3), 9. Retrieved from http://ir.lib.uwo.ca/iipj/vol3/iss3/9

State of Michigan. (2016). Flint Water Advisory Task Force Final Report. Retrieved from http://www.michigan.gov/documents/snyder/FWATF_FINAL_REPORT_21March2016_517805_7.pdf

Statistics Canada. (2015). Health Regions: Boundaries and Correspondence with Census Geography, (82-402-X). Statistical Registers and Geography Division for the Health Statistics Division. Retrieved from http://www.statcan.gc.ca/pub/82-402-x/2015002/maps-cartes/rm-cr/on_south_ref_11_2015-eng.pdf

Tolhurst, E. (2012). Grounded Theory Method: Sociology's Quest for Exclusive Items of Inquiry [44 paragraphs]. Forum: Qualitative Social Research, 13(3), Art. 26.

Turgeon, S., Rodriguez, M. J., Thériault, M., \& Levallois, P. (2004). Perception of drinking water in the Quebec City region (Canada): The influence of water quality and consumer location in the distribution system. Journal of Environmental Management, 70(4), 363-373. https://doi.org/10.1016/j.jenvman.2003.12.014

Upper Grand District School Board. (2016). Our Communities. Retrieved from https://www.ugdsb.on.ca/world/article.aspx?id=31715.

Vaismoradi, M., Turunen, H., \& Bondas, T. (2013). Content analysis and thematic analysis: Implications for conducting a qualitative descriptive study. Nursing \& Health Sciences, 15(3), 398-405. https://doi.org/10.1111/nhs.12048

Wellington-Dufferin-Guelph Public Health. (2016). A report on mental health in Wellington, Dufferin and Guelph. Retrieved from https://www.wdgpublichealth.ca/sites/default/files/file-attachments/report/hs_report_2016-report-on-mental -health-in-wdg-fullreport_access.pdf

\section{Copyrights}

Copyright for this article is retained by the author(s), with first publication rights granted to the journal.

This is an open-access article distributed under the terms and conditions of the Creative Commons Attribution license (http://creativecommons.org/licenses/by/4.0/). 